\title{
ANL/CHM/PP- 87026
}

\section{ACTINIDE COMPLEXATION KINETICS: RATE AND MECHANISM OF DIOXONEPTUNIUM (V) REACTION WITH CHLOROPHOSPHONAZO III}

Glenn Fugate, Janine F. Feil-Jenkins, James C. Sullivan, and Kenneth L. Nash

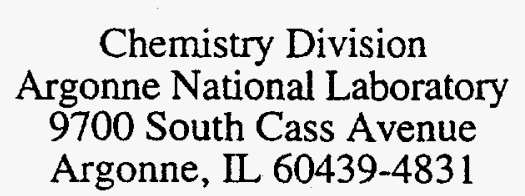

Chemistry Division Argonne National Laboratory 9700 South Cass Avenue

Abstract

The rates of complex formation and dissociation in the system $\mathrm{NpO}_{2}{ }^{+}$. Chlorophosphonazo III (2, 7-bis(4-chlorophosphonobenzeneazo)-1, 8-dihydroxynapthalene-3, 6-disulfonic acid-CLIII) has been investigated by stopped-flow spectrophotometry. In addition, limited studies have been made of the rates of reaction of $\mathrm{La}^{3+}, \mathrm{Eu}^{3+}, \mathrm{Dy}^{3+}$, and $\mathrm{Fe}^{3+}$ with CLIII. The rate determining step in each system is an intramolecular process, the $\mathrm{NpO}_{2}{ }^{+}-\mathrm{CLIII}$ reaction proceeding by a first order approach to equilibrium in the acid range from 0.1 to $1.0 \mathrm{M}$. Complex formation occurs in a process independent of acidity, while both acid dependent and independent dissociation pathways are observed. The activation parameters for the complex formation reaction are $\Delta \mathrm{H}^{*}=46.2( \pm 0.3) \mathrm{kJ} / \mathrm{m}$ and $\Delta S^{*}=7( \pm 1) \mathrm{J} / \mathrm{mK}(I=1.0 \underline{\mathrm{M}})$. The corresponding parameters for the acid dependent and independent dissociation pathways are $\Delta H^{*}=38.8( \pm 0.6) \mathrm{kJ} / \mathrm{m}, \Delta \mathrm{S}^{*}=-96( \pm 18) \mathrm{J} / \mathrm{mK}$, $\Delta H^{*}=70.0( \pm 0.1) \mathrm{kJ} / \mathrm{m}$ and $\Delta S^{*}=17( \pm 1) \mathrm{J} / \mathrm{mK}$, respectively. An isokinetic relationship is observed between the activation parameters for CLIII complex formation with $\mathrm{NpO}_{2}+$, $\mathrm{UO}_{2}{ }^{2+}, \mathrm{Th}^{4+}$. and $\mathrm{ZH}^{++}$. The rates of CLIII complex formation reactions for $\mathrm{Fe}^{3+}, \mathrm{Zr}^{4+}$, $\mathrm{NpO}_{2}+, \mathrm{UO}_{2}{ }^{2+}, \mathrm{Th}^{4+}, \mathrm{La}^{3+}, \mathrm{Eu}^{3+}$, and $\mathrm{Dy}^{3+}$ correlate with the cation radius rather than the charge/radius ratio.

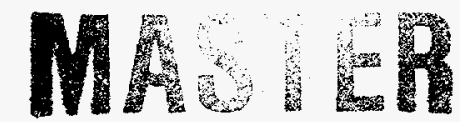

\footnotetext{
"Work performed under the auspices of the Otfice of Basic Energy Sciences, Division of Chemical Sciences.

U. S. Department of Energy, under contract number W-31-109-ENG-38.

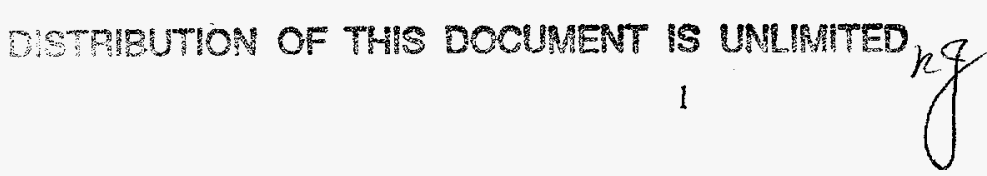

The submitted manuscript has been authored by a contractor of the U.S. Government under contract No. W-31-109-ENG-38. Accordingly, the U.S. Government retains

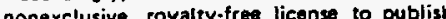
nonexclusive, rovalty-free liconse to publish or reproduce the publithed form of this contribution, or allow others to do 20 , for 


\section{DISCLAIMER}

Portions of this document may be illegible in electronic image products. Images are produced from the best available original document. 


\section{Introduction}

The rates of complex formation reactions of $f$ elements with complex ligand species have been most extensively investigated for trivalent lanthanide cations. 1 By comparison complexation kinetics of actinide cations has received relatively little attention, particularly for the transuranium elements. ${ }^{2}$ However, since the light $5 \mathrm{f}$ elements demonstrate coordination properties intermediate between the $4 \mathrm{f}$ and $\mathrm{d}$-transition elements, investigation of their complexation kinetics could provide an important linkage between these classes of metal ions. In particular, the effects of the multiple oxidation states of actinides and the sterically hindered dioxo cations on complex formation and dissociation rates are of interest.

The ligand, Chlorophosphonazo III (CLIII), (2,7-bis(4-chloro-2-phosphonobenzeneazo)-1, 8-dihydoxynapthalene-3, 6-disulfonic acid) is an excellent probe for studies that delineate the influence of the properties of $4 \mathrm{f}$ and $5 \mathrm{f}$ metal ions (ionic radius, formal charge, electronic structure) upon the rates of complexation reactions. Phosphonic acid complexants are somewhat unusual in their ability to form strong complexes with polyvalent metal ions in media of moderate acidity. We have recently developed significant new information on the thermodynamics and kinetics of lanthanide and actinide complexation by phosphonates. ${ }^{3-9}$ A previous study ${ }^{3}$ has demonstrated an unexpected inverse correlation between cation radii and rates for CLIII complex formation with the tetravalent cations of $\mathrm{Zr}(\mathrm{IV})$ and $\mathrm{Th}(\mathrm{IV})$. A subsequent investigation of the kinetics of uranyl complexation by CLIII+ indicated a distinct difference between the mechanism at low acidity and in molar acid, and established the relative rate for complexation by CLIII of $\mathrm{Th}^{4+}>\mathrm{UO}_{2}{ }^{2+}>\mathrm{Zr}^{4+}$. The present study explores the effect of variation in the formal charge in a restricted cation geometry by comparison of the results previously obtained for dioxouranium(VI) with dioxoneptunium(V) as the cation. A limited number of experiments 
have treated lanthanide and Fe(III) complex formation rates with CLIII to examine trivalent cation behavior in this system.

\section{Experimental}

Reagents. The perchloric acid and sodium perchlorate stock solutions were prepared and standardized by conventional techniques. The CLIII was purchased from Fluka and stock solutions were prepared by weight. To insure oxidation state purity of the $\mathrm{Np}(\mathrm{V})$, an aliquot of an existing stock solution was first oxidized (to $\mathrm{Np}(\mathrm{VI})$ ) with sodium bromate, then reduced to $\mathrm{Np}(\mathrm{V})$ with sodium nitrite. $\mathrm{NaOH}$ was added to precipitate $\mathrm{NpO}_{2}(\mathrm{OH})$, and the precipitate washed with distilled water until the supernatant was pH neutral. The washed hydroxide readily dissolved in $1 \mathrm{M} \mathrm{HClO}$. The $\mathrm{Np}$ stock solution was assayed spectrophotometrically at $617 \mathrm{~nm}$ using the molar absorptivity of $23.7 \mathrm{M}^{-1} \mathrm{~cm}^{-1} .10 \mathrm{La}\left(\mathrm{ClO}_{4}\right)_{3}, \mathrm{Eu}\left(\mathrm{ClO}_{4}\right)_{3}$, and $\mathrm{Dy}\left(\mathrm{ClO}_{4}\right)_{3}$ solutions were prepared from previously characterized lab stocks. Iron solutions were prepared from $\mathrm{Fe}\left(\mathrm{ClO}_{4}\right)_{3}$ solid and standardized spectrophotometrically with KSCN.

Procedures. Most of the kinetic studies used a Hi-Tech stopped flow instrument with a rapid-scan diode array detection system. A 486DX2 computer used the Hi-Tech data acquisition and kinetic analysis program. This system permits observations of both free ligand disappearance and complex formation in a single experiment and enables kinetic analysis at multiple wavelengths. Several replicate determinations were made for each set of experimental conditions. For the lanthanides and Fe(III) studies, the photomultiplier detector was used instead of the diode array.

CLIII was the limiting reagent in most experiments, held constant at $4 \times 10^{-5} \underline{\mathrm{M}}$. Neptunium concentrations were varied between $2 \times 10^{-5} \underline{\mathrm{M}}$ and $1 \times 10^{-4} \underline{\mathrm{M}}$. Ionic strength was constant at $1.0 \underline{\mathrm{M}}$ except for selected experiments which examined the effect of ionic 
strength on the rate. The effect of $\left[\mathrm{H}^{+}\right]$and temperature on the rate was also determined. For the lanthanides, it was possible to measure only a single rate at equimolar concentrations $\left([\mathrm{Ln}]=[\mathrm{CLIII}]=4 \times 10^{-5} \underline{\mathrm{M}}\right)$ and one acidity $(2 \underline{\mathrm{M}})$. Reaction rates were too fast for the stopped-flow technique at higher [Ln] or lower acid. One set of experiments was run in the $\mathrm{Fe}(\mathrm{III})$-CLIII system at $0.1 \mathrm{M}$ ionic strength, $\mathrm{T}=25.0^{\circ} \mathrm{C}$, and $\left[\mathrm{H}^{+}\right]=0.02$ $\underline{M}$ to measure the complex formation rate for this system.

\section{Results and Discussion}

The decrease in absorptivity of CLIII at $550 \mathrm{~nm}$ and the increase in absorptivity at 614 and $664 \mathrm{~nm}$ due to the formation of a $\mathrm{Np}(\mathrm{V})$-CLIII complex at $25^{\circ} \mathrm{C}$ and reactant concentrations of $[\mathrm{Np}(\mathrm{V})]=[\mathrm{CLIII}]=4.0 \times 10^{-5} \underline{\mathrm{M}}\left(\left[\mathrm{H}^{+}\right]=0.1 \underline{\mathrm{M}}\right)$ are shown in Figure 1a. The spectral characteristics at $0.1 \underline{\mathrm{M}}$ acid are consistent with literature reports on the $\mathrm{Np}(\mathrm{V})$ CLIII complex, though the $\lambda_{\max }$ values are $6-8 \mathrm{~nm}$ lower than in the literature report. ${ }^{11}$ The essential double maximum for the metal complexes is observed in each of the systems previously reported. For $\mathrm{Np}(\mathrm{V})$ experiments at $1.0 \underline{\mathrm{M}}$ acid (Figure 1b), the metal complex absorption band at $614 \mathrm{~nm}$ is not observed.

Ferguson, et al. ${ }^{12}$ have reported spectra of CLIII as a function of $\mathrm{pH}$. Their results combined with the protonation constants reported by Men'kov and Nepomnyashchaya 13 can be used to suggest a correlation between the spectral bands for the free CLIII ligand and specific ligand protonated species. The broad band at $550 \mathrm{~nm}$ correlates with the free ligand species $\mathrm{H}_{8} \mathrm{~L}, \mathrm{H}_{7} \mathrm{~L}^{-}, \mathrm{H}_{6} \mathrm{~L}^{2-}, \mathrm{H}_{5} \mathrm{~L}^{3-}$, which represent species generated by consecutive ionization of the two sulfonates and first ionization of each phosphonate group. The 660 $\mathrm{nm}$ band is correlated with ionization of the second proton from each phosphonate while the $614 \mathrm{~nm}$ band corresponds to the ligand species created by ionization of the phenols. These spectral features in CLIII are stimulated at lower $\mathrm{pH}$ by metal-ion coordination. 
In strong acid media $(0.7-1.0 \underline{\mathrm{M}})$ and at low $[\mathrm{Np}(\mathrm{V})]$, it appears that the metal ion is coordinated only to the phosphonate groups of CLIII (Figure 2a), as evidenced by activation of the $664 \mathrm{~nm}$ chromophore only. In more dilute acid and higher [Np(V)], the equilibrium apparently shifts to a different species in which the metal ion bound to phosphonate displaces the protons from the phenols to activate the $614 \mathrm{~nm}$ chromophore forming a tetradentate complex (Figure $2 \mathrm{~b}$ ). This tetradentate structure has been previously suggested by Budesinsky. ${ }^{14}$ It is important to note that the kinetic results were apparently not effected by this distribution of species implying that there is a common mechanism for the dissociation of both the bidentate and tetradentate species.

The tetradentate complex involves the formation of one six-member ring between the metal ion and the two phenol groups and two 10-member rings involving the metalphosphonate-phenol groups. Ordinarily, the latter would not be expected to contribute substantially to complex stability. However, molecular mechanics calculations indicate 4 that the CLIII ligand is quite "stiff". As a result, no significant vibrational or rotational degrees of freedom are lost by the ligand upon formation of the tetradentate complex. The stiffness of CLIII imparts a preorganization of the ligand ionic atoms akin to that observed in crown ethers.

The values calculated for the first order rate parameter $\mathrm{k},\left(\mathrm{s}^{-1}\right)$, at $4 \times 10^{-5} \mathrm{M} \mathrm{Np}(\mathrm{V})$ and CLIII, $\left[\mathrm{H}^{+}\right]=0.1, \mathrm{~T}=25.0^{\circ} \mathrm{C}$ are $23( \pm 2)$ at $550 \mathrm{~nm}, 27( \pm 1)$ at $614 \mathrm{~nm}$ and 26.1 $( \pm 0.8)$ at $664 \mathrm{~nm}$ (where the uncertainties are at the $\pm 2 \sigma$ level). The fact that the kinetic data are fit by a first order rate law under the second order conditions indicates that the rate determining step is an intramolecular process. ${ }^{15}$ Under the same conditions as above except $[$ CLIII $]=8 \times 10^{-5} \underline{\mathrm{M}}$, the value calculated for $\mathrm{k}=30( \pm 4) \mathrm{s}^{-1}$. This result implies the absence of 1:2 ( $\mathrm{Np}(\mathrm{V})$ :CLIII) complexes under these conditions. The rate is linearly 
dependent upon the $\mathrm{Np}(\mathrm{V})$ concentration as is illustrated in Figure 3. Similar linear plots with finite positive intercept are observed over the ranges of temperature and $\left[\mathrm{H}^{+}\right]$that were studied.

Table 1 summarizes the values calculated for the slopes $\left(k_{1}\right)$ and intercept $\left(k_{\text {int }}\right)$ of the $\mathrm{k}_{\mathrm{obs}}$ vs $[\mathrm{Np}]_{\mathrm{t}}$ plots as a function of $\left[\mathrm{H}^{+}\right]$and $\mathrm{T}$. The slopes are independent of $\left[\mathrm{H}^{+}\right]$while the intercept values increase with increasing $\left[\mathrm{H}^{+}\right]$. The linear relationship between $\mathrm{k}_{\mathrm{int}}$ and $\left[\mathrm{H}^{+}\right]$is maintained throughout the temperature range investigation. The empirical form of the rate law is:

$$
\mathrm{k}_{\mathrm{obs}}=\mathrm{k}_{1}[\mathrm{NpV}]+\mathrm{k}_{2}+\mathrm{k}_{3}\left[\mathrm{H}^{+}\right]
$$

where $k_{1}$ corresponds to the complex formation reaction and $k_{2}, k_{3}$ are respectively acid independent and acid dependent dissociation rate constants. The rate constants as a function of temperature are shown in Table 2. From these rate constants we can calculate the \% dissociation by both acid independent and acid dependent pathways. They range from a low of $\sim 1 \%$ acid dependent at $\left[\mathrm{H}^{+}\right]=0.1, \mathrm{~T}=25.0^{\circ} \mathrm{C}$ to $47 \%$ at $\left[\mathrm{H}^{+}\right]=1.0, \mathrm{~T}=$ $5.0^{\circ} \mathrm{C}$.

We were able to measure the rate of complex formation for the $\mathrm{La}^{3+}$-CLIII, $\mathrm{Eu}^{3+}$ CLIII, and Dy ${ }^{3+}$-CLIII systems under only one set of conditions. At $2 \underline{\mathrm{M}}$ acid, the second order rate constants are $\mathrm{k}_{\mathrm{La}}=4.24( \pm 0.46) \times 10^{7} \underline{\mathrm{M}}^{-1} \mathrm{~s}^{-1}, \mathrm{k}_{\mathrm{Eu}}=4.79( \pm 0.96) \times 10^{7} \underline{\mathrm{M}}^{-1} \mathrm{~s}^{-1}$, $\mathrm{k}_{\mathrm{Dy}}=2.54( \pm 0.57) \times 10^{7} \underline{\mathrm{M}}^{-1} \mathrm{~s}^{-1}$. These reaction rates are computed based on a small absorptivity change, implying that the degree of Ln-CLIII complex formation under these conditions is slight. The rates for this reaction are approximately an order of magnitude slower than the reported rates of water exchange for lanthanide aquo ions, ${ }^{16}$ implying that water exchange on the free $\mathrm{Ln}^{3+}$ cation is not rate limiting. Micskei et al. (17) have reported that the rate of exchange of inner-sphere wafer molecules in $\mathrm{Gd}^{3+}$ complexes with 
aminopolycarboxylate ligands (determined by ${ }^{17} \mathrm{O}$ NMR spectrometry) are about an order of magnitude slower than that of the aquo ion $\left(\mathrm{Gd}\left(\mathrm{H}_{2} \mathrm{O}\right)_{8}{ }^{3+}\right)$. The similarity between their results and ours suggests that solvent exchange in the metal complex may be important in the $\mathrm{Ln}^{3+}$-CLIII system as well.

In the $\mathrm{Fe}$ (III)-CLIII system, no appreciable reaction was observed at 1-2 $\underline{\mathrm{M}}$ acid media. The rate of $\mathrm{Fe}$ (III)-CLIII complex formation was measurable at $0.02 \underline{\mathrm{M} \mathrm{HClO}} 4, \mathrm{I}=$ $0.1 \mathrm{M}$ monitoring the rate of disappearance of the CLIII band at $550 \mathrm{~nm}$. The data were resolved into two parallel first order processes. Both rate constants ( $k$ and $\left.k^{\prime}\right)$ were a linear function of $\left[\mathrm{Fe}^{3+}\right]$. The intercepts of the plots were not distinguishable from zero. Second order rate constants for the two processes were $1.54( \pm 0.04) \times 10^{4} \underline{\mathrm{M}}^{-1} \mathrm{~s}^{-1}$ and $1.70( \pm 0.02) \times 10^{3} \underline{\mathrm{M}}^{-1} \mathrm{~s}^{-1}$. A two component rate was previously reported in the $\mathrm{Zr}^{4+}$ CLIII system, and interpreted in terms of parallel pathways describing the eaction of CLIII with $\mathrm{Zr}^{4+}$ and $\mathrm{Zr}(\mathrm{OH})^{3+}$. It is likely that a similar argument would explain the $\mathrm{Fe}^{3+} \mathrm{CLIII}$ results.

Activation parameters for the formation and dissociation of the $\mathrm{Np}(\mathrm{V})$-CLIII complex are given in Table 3. Standard deviations in the activation parameters reflect the experimental uncertainties in the resolved rate parameters. Activation parameters were also calculated for the Np-CLIII results in $0.1 \mathrm{M} \mathrm{HClO}_{4}$ (for complex formation only). The most notable feature of this table is the near zero $\Delta S^{*}$ for complex formation and acid independent dissociation at $\mathrm{I}=1.0 \underline{\mathrm{M}}$.

Calculations based on literature values for CLIII protonation constants ${ }^{13}$ indicate that both phosphonate groups of CLIII are fully-protonated at $\left[\mathrm{H}^{+}\right]>0.1 \underline{\mathrm{M}} .{ }^{4}$ The dominant ligand species is $\mathrm{H}_{6}(\mathrm{CLIII}), 2-$ assuming both sulfonate groups are ionized. We have 
assumed $\mathrm{NpO}_{2}\left(\mathrm{H}_{2} \mathrm{O}\right)_{4}{ }^{+}$is the dominant species in discussion of a mechanism. The hydration number of $\mathrm{NpO}_{2}+$ does not effect the mechanism.

The absence of any significant acid dependence in the complex formation rate requires either no $\mathrm{H}^{+}$loss in the overall reaction, or that deprotonation occurs in steps subsequent to the rate-determining-step. Earlier investigations of the thermodynamics of Th(IV) complexes with methane diphosphonic acid indicated the formation of complexes without $\mathrm{H}^{+}$displacement from $\mathrm{PO}_{3} \mathrm{H}_{2}$, the $\mathrm{Th}^{4+}$ ion interacting through the phosphoryl oxygen $(\mathrm{P}=\mathrm{O})$. We have drawn the complexed species with $\mathrm{NpO}_{2}{ }^{+}$bound to the phosphoryl oxygen $(\mathrm{P}=\mathrm{O})$, but we have no a priori evidence that the phosphonates are not ionized upon binding $\mathrm{NpO}_{2}{ }^{+}$. Certain mechanistic considerations for acid catalyzed dissociation favor the latter picture (i.e., $\mathrm{NpO}_{2}-\mathrm{O}-\mathrm{P}=\mathrm{O}$ ).

To accommodate the experimental observations and these structural features, the following sequence of reactions is postulated to describe $\mathrm{Np}(\mathrm{V})$-CLIII complex formation):

$$
\begin{gathered}
\mathrm{NpO}_{2}\left(\mathrm{H}_{2} \mathrm{O}\right)_{4}^{+}+\mathrm{H}_{6}(\mathrm{CLIII})^{2-} \rightleftharpoons \mathrm{NpO}_{2}\left(\mathrm{H}_{2} \mathrm{O}\right)_{4}+\cdot \mathrm{H}_{6}(\mathrm{CLIII})^{2-} \\
\mathrm{NpO}_{2}\left(\mathrm{H}_{2} \mathrm{O}\right)_{4}+\cdot \mathrm{H}_{6}(\mathrm{CLIII})^{2-} \rightleftharpoons\left(\mathrm{NpO}_{2}\left(\mathrm{H}_{2} \mathrm{O}\right)_{3} \mathrm{H}_{6}(\mathrm{CLIII})\right)^{-}+\mathrm{H}_{2} \mathrm{O} \\
\left(\mathrm{NpO}_{2}\left(\mathrm{H}_{2} \mathrm{O}\right)_{3} \mathrm{H}_{6}(\mathrm{CLIII})\right)^{-} \rightleftharpoons\left[\mathrm{NpO}_{2}\left(\mathrm{H}_{2} \mathrm{O}\right)_{2} \mathrm{H}_{6}(\mathrm{CLIII})^{-}\right]^{\ddagger}+\mathrm{H}_{2} \mathrm{O}
\end{gathered}
$$

Reaction 3 is the formation of the outer sphere "ion pair" or solvent-separated complex (in accordance with the Eigen mechanism). In 4 , a water molecule is displaced from the inner coordination sphere by one of the unionized phosphonate groups $\left(-\mathrm{PO}_{3} \mathrm{H}_{2}\right)$ to form the precursor complex. The net cratic entropy for $3+4$ should be about zero. The transformation of the precursor complex to the activated complex is given as reaction 5 . The small $\Delta S^{*}$ implies that the precursor and activated complex are structurally similar. 
Through this step, the reaction sequence is independent of $\left[\mathrm{H}^{+}\right]$. The spectral features shown in Figure 1 imply that the activated complex has two relaxation pathways available leading to the formation of the bidentate or tetradentate complex (Figure 2).

At $0.1 \underline{\mathrm{M}}$ ionic strength, the second order rate constant for complex formation $(\mathrm{T}=$ $25.0{ }^{\circ} \mathrm{C},\left[\mathrm{H}^{+}\right]=0.1 \underline{\mathrm{M}}$ ) is 2.4 times faster than at $\mathrm{I}=1.0 \underline{\mathrm{M}}$ ionic strength $\left(3.08 \times 10^{5} \mathrm{M}^{-1} \mathrm{~s}^{-1}\right.$ vs. $\left.1.28 \times 10^{5} \mathrm{M}^{-1} \mathrm{~s}^{-1}\right)$. The activation parameters are $\Delta \mathrm{H}^{*}=60.5( \pm 0.1)$ $\mathrm{kJ} / \mathrm{m}, \Delta \mathrm{S}^{*}=62( \pm 1) \mathrm{J} / \mathrm{mK}$, both of which are more positive than at $\mathrm{I}=1.0 \underline{\mathrm{M}}$. By comparison with the activation parameters at $\mathrm{I}=1.0 \underline{\mathrm{M}}$, calculations indicate that the increased energy barrier $\left(\Delta \mathrm{H}^{*}\right)$ opposes the rate of complexation (by $\sim 300$ ) while the decreased order in the system $\left(\Delta S^{*}\right)$ leads to a net increase in the rate (by $\sim 750$ ) of complex formation. One possible explanation for the higher $\Delta S^{*}$ is the loss of a second inner-sphere water molecule upon transformation from the precusor to activated complex. Such a process would be facilitated in a less dense medium.

Considering now the rate of complex dissociation, spectral evidence indicated that the species we have designed as the bidentate chelate is dominant for $[\mathrm{CLII}]>\left[\mathrm{NpO}_{2}{ }^{+}\right]$and at $\left[\mathrm{H}^{+}\right] \geq 0.7 \underline{\mathrm{M}}$. The tetradentate species is indicated in more dilute acid. There is substantial overlap between these species. Because the data are well-correlated independent of the species distribution, we conclude that a common mechanism accounts for the dissociation of both the bidentate and tetradentate complexes. The rate of $\mathrm{NpO}_{2}{ }^{+}-\mathrm{O}=\mathrm{P}(\mathrm{OH})_{2}-\mathrm{R}$ bond breaking must therefore be rate limiting.

The parallel dissociation pathways correspond to the spontaneous breaking of the $\mathrm{NpO}_{2}-\mathrm{O}=\mathrm{P}$ bond, and the $\mathrm{H}^{+}$catalyzed dissociation of the $\mathrm{Np}-\mathrm{O}=\mathrm{P}$ bond. The small positive $\Delta \mathrm{S}^{*}$ for the $\mathrm{H}^{+}$independent pathway is consistent with minimal structural difference between the stable complex and the activated complex. The relatively large $\Delta \mathrm{H}^{*}$ 
implies that this is a moderately strong bond. The acid catalyzed dissociation reaction is characterized by a large negative $\Delta \mathrm{S}^{*}(-96 \mathrm{~J} / \mathrm{m}-\mathrm{K})$, consistent with an associative reaction. The enthalpy barrier to dissociation is considerably reduced for this reaction $\left(\Delta \mathrm{H}^{*}=\right.$ $38.8 \mathrm{~kJ} / \mathrm{m})$.

Correlation of CLIII Rate Data. Though isokinetic plots must be approached with caution (as discussed by Linert (18)), the correlation of $\Delta \mathrm{H}^{*}$ and $\Delta \mathrm{S}^{*}$ for a series of related reactions can provide insight into the nature of the common reaction. We have prepared such a plot for the rate of complex formation between $\mathrm{Np}(\mathrm{V}), \mathrm{U}(\mathrm{VI}),{ }^{4} \mathrm{Th}(\mathrm{IV})^{3}$ and $\mathrm{Zr}(\mathrm{IV})^{3}$ with CLIII. These metal ions represent formal charges from +1 to +4 and present the geometric restriction of the dioxo cations for $\mathrm{Np}(\mathrm{V})$ and $\mathrm{U}(\mathrm{VI})$. The isokinetic plot for this system is shown in Figure 4. The activation parameters $\left(\Delta \mathrm{H}^{*}\right.$ and $\left.\Delta \mathrm{S}^{*}\right)$ are roughly proportional to the charge density of the cations $\left(\mathrm{Zr}^{4+}>\mathrm{Th}^{4+}>\mathrm{UO}_{2}{ }^{2+}=\mathrm{NpO}_{2}\right)$. The lower activation entropies and the apparent leveling of the relationship between $\Delta \mathrm{H}^{*}$, $\Delta S^{*}$ and $z / r$ of the dioxo cations may reflect the tendency of the "yl" oxygens to participate in hydrogen bonding interactions with the protonated phosphonate groups ${ }^{7}$ of CLIII. The planar arrangement of donor groups imposed by the dioxo cations does not disrupt the isokinetic relationship. The isokinetic relationship suggests that the ligand donor atoms adopt a similar planar configuration in its complexes with the nominally spherical ions $\mathrm{Th}(\mathrm{IV})$ and $\operatorname{Zr}(\mathrm{IV})$. It also confirms that the relatively slow rate of the $\mathrm{Zr}(\mathrm{IV})$-CLIII complex formation reaction is not the result of a changed reaction mechanism.

Superficially, the relative rate of complex formation of $\mathrm{Np}(\mathrm{V}), \mathrm{U}(\mathrm{VI})$ and $\mathrm{Th}(\mathrm{IV})$ complexes with CLIII in 1-2 $\underline{\mathrm{M}}$ acid is in the expected order for a reaction controlled by electrostatic factors. However, earlier results on $\mathrm{Zr}(\mathrm{IV})$ and additional information developed in this study on the trivalent ions La, Eu, Dy, and Fe(III) violate this 
relationship. The lanthanides react faster than $\mathrm{Th}(\mathrm{IV})$ while both $\mathrm{Fe}(\mathrm{III})$ and $\mathrm{Zr}$ (IV) react more slowly. Clearly, the electrostatic argument does not correlate this extended series.

In Figure 5 are presented the rates of formation for $\mathrm{Np}(\mathrm{V}), \mathrm{U}(\mathrm{VI}), \mathrm{Th}(\mathrm{IV}), \mathrm{Zr}(\mathrm{IV})$, $\mathrm{La}(\mathrm{III}), \mathrm{Eu}(\mathrm{III}), \mathrm{Dy}(\mathrm{III})$, and $\mathrm{Fe}(\mathrm{III})$ complexes with CLIII as a function of the cation radii. The radii are from Shannon ${ }^{19}$ and correspond to $\mathrm{CN}=6$ for $\mathrm{U}(\mathrm{VI}), \mathrm{Np}(\mathrm{V}), \mathrm{Zr}(\mathrm{IV})$, and $\mathrm{Fe}$ (III) (low spin) and $\mathrm{CN}=8$ for $\mathrm{Th}(\mathrm{IV})$ and the lanthanides. The linear correlation is 0.986 for this series indicating that the size of the cation governs the rate of complexation of the metals. This relationship is supported qualitatively by Ferguson et al. ${ }^{12}$ who report that CLIII reacts with the large $\mathrm{Ca}^{2+}$ cation at $\mathrm{pH} 2$, but not with $\mathrm{Mg}^{2+}$ at $\mathrm{pH}<7$. Molecular mechanics calculations provide no particular insight to the relative rates of the larger cations. These calculations do indicate some fractional structural stress in CLIII when coordinated to the small $\mathrm{Fe}(\mathrm{III})$ and $\mathrm{Zr}(\mathrm{IV})$ in the tetradentate coordination mode. A rather large "cavity" is formed by the four oxygen donor atoms in the free CLIII ligand. Calculations suggest a hemispherical "hole" in CLIII with a diameter of $\sim 4.6-4.7 \AA$. This hole is quite close to the estimated diameter of the hydrated lanthanide cations. ${ }^{20}$ The nominal good fit of such species in CLIII should promote hydrogen bonding between the ligand donor groups and the hydrated cation in the solvent-separated species. As the metal ion and its primary coordination sphere shrink, the metal ion is less strongly held by these hydrogen bonding interactions, and the smaller metal ion can more easily escape from the nacent complex. Electrostatic effects describing attraction of metal by ligand must be of secondary importance partly due to the shielding of charge by the hydration sphere of the cation in the precursor complex. 


\section{Conclusion}

We can draw several conclusions relevant to metal ion coordination by this ligand system, and to the comparison of metal complexation rates of $d$ and $f$ transition elements in coordination compounds from this investigation. Characterization of metal complex spectra suggest that the stable complexes are tetradentate with the metal ions coordinated to both phosphonates and both phenols in CLIII in dilute acid. At $>0.7 \mathrm{M}$ acid and low concentrations of $\mathrm{NpO}_{2}^{+}$, the metal ion is bound only to the phosphonates. $\mathrm{Np}$ results suggest that initial coordination occurs between the metal ion and phosphonate groups. However, this association appears to occur without ionization of the phosphonate, at $\left[\mathrm{H}^{+}\right]$ $\geq 0.1 \underline{\mathrm{M}}$. The rate of dissociation of $\mathrm{NpO}_{2}+$ from the phosphonate groups is rate limiting whether the phenols are bound or not.

An isokinetic relationship exists for the formation of CLIII complexes with $\mathrm{NpO}_{2}{ }^{+}$, $\mathrm{UO}_{2}{ }^{2+}, \mathrm{Zr}^{4+}$, and $\mathrm{Th}^{4+}$ suggesting the commonality of the mechanisms. Activation parameters are superficially correlated with the charge density $(\mathrm{z} / \mathrm{r})$ of the metal ions, but are only slightly effected by the presence of the "yl" oxygens in $\mathrm{NpO}_{2}{ }^{+}$and $\mathrm{UO}_{2}{ }^{2+}$. In contrast, reaction rates are correlated with cation size irrespective of the charge. This suggest that the inner sphere waters of the metal ion in the precursor complex partially shield the ligand from the cation charge. It also suggests that hydrogen bonding between waters of the inner hydration sphere and ligand donor atoms is important in determining the rate of reaction. The observation of a kinetics based size-selectivity effect in a ligand only partially preorganized further suggests that it may be possible to design size-selective ligands without large-scale, rigid organization of ligand donor atoms (as in crown ethers). 


\title{
REFERENCES
}

(1) Nash, K. L.; Sullivan, J. C. "Kinetics of complexation and redox reactions of the lanthanides in aqueous solution" in Handbook of the Physics and Chemistry of Rare Earths, Vol. 15, (K. A. Gschneidner, Jr. and L. Eyring, eds.) Elsevier Science Publishers, B.V., pp. 347-391, 1991.

(2) Nash K. L.; Sullivan J. C. "Kinetics and mechanisms of actinide redox and complexation reactions" in Advances in Inorganic and Bioinorganic Reaction Mechanisms, (A. G. Sykes, ed.), Academic Press, London, pp. 205-213, 1986.

(3) Feil-Jenkins, J. F.; Nash, K.; Sullivan, J. C. "Kinetics of the complexation reactions between Th(IV), Zr(IV) and Chlorophosphonazo III" Radiochim. Acta, in press.

(4) Feil-Jenkins, J. F.; Sullivan, J. C.; Nash, K. L. "Kinetics of the Complexation of dioxouranium(VI) with Chlorophosphonazo III" Radiochim. Acta, in press.

(5) Hines, M. A.; Sullivan, J. C.; Nash, K. L. Inorg. Chem. 1993, 32, 1820.

(6) Nash, K. L.; Horwitz, E. P. Inorg. Chim. Acta 1990, 169, 245.

(7) Nash, K. L. Radiochim. Acta 1993, 61, 147.

(8) Nash, K. L. Radiochim. Acta 1991, 54, 171.

(9) Nash, K. L.; Rao, L. F.; Choppin, G. R. "A calorimetric and laser induced fluorescence investigation of the complexation geometry of selected europium(gem)diphosphonate complexes in acidic solutions" Inorganic Chemistry, in press.

(10) Sjoblom, R.; Hindman, J. C. J. Am. Chem. Soc. 1951, , 1744.

(11) Chudinov, E. G.; Yakovlev, G. N. Soviet Radiochemistry 1962, 4(5), 526. Translated from Radiokhimiya 1962, 4(5), 601 .

(12) Ferguson, J. W.; Richard, J. J.; O'Laughlin, J. W.; Banks, G. V. Anal. Chem. 1964, $36,796$.

(13) Men'kov, A. A.; Nepomnyashchaya, N. A. Russian Journal of Inorganic Chemistry 1977, 22(8), 1155. Translated from Zhurnal Neorganicheskii Khimiya 1977, 22, 2135.

(14) Budesinsky, B. "Monoarylazo and bis(arylazo) derivatives of chromotropic acid as photometric reagents" in Chelates in Analytical Chemistry, Vol. 2 (H. A. Flaschka and A. J. Barnard, Jr. eds.) Marcel Dekker, New York, pp. 1-91, 1969.

Nyssen, G. A.; Margerum, D. W. Inorg. Chem. 1970, 9, 1814.

Cossy, C.; Helm, L.; Merbach, A. E. Inorg. Chem. 1989, 28, 2699.

Micskei, M.; Heum, L.; Brücher, E.; Merbach, A. E. Inorg. Chem. 1993, 32, 3844.

Linert, W. Chem. Soc. Rev. 1994, 23, 429.

Shannon, R. D. Acta Cryst. A 1976, 32, 751.

Rizkalla, E. N.; Choppin, G. R. "Lanthanides and actinides hydration and hydrolysis" in Handbook of the Physics and Chemistry of the Rare Earths, Vol. 18 (K. A. Gschneidner, Jr. and L. Eyring, eds.) Elsevier Science Publishers, Amsterdam, 1994, pp. 529-558.

\section{DISCLAIMER}

\begin{abstract}
This report was prepared as an account of work sponsored by an agency of the United States Government. Neither the United States Government nor any agency thereof, nor any of their employees, makes any warranty, express or implied, or assumes any legal liability or responsibility for the accuracy, completeness, or usefulness of any information, apparatus, product, or process disclosed, or represents that its use would not infringe privately owned rights. Reference herein to any specific commercial product, process, or service by trade name, trademark, manufacturer, or otherwise does not necessarily constitute or imply its endorsement, recommendation, or favoring by the United States Government or any agency thereof. The views and opinions of authors expressed herein do not necessarily state or reflect those of the United States Government or any agency thereof.
\end{abstract}




\section{Figure Captions}

Figure 1. Diode array traces of the reaction between $4.0 \times 10^{-5} \mathrm{M} \mathrm{NpO}_{2}^{+}$and $4.0 \times 10^{-5} \underline{\mathrm{M}}$ Chlorophosphonazo $\mathrm{III}$ as a function of acidity at $\mathrm{I}=1.0 \underline{\mathrm{M}}$, $\mathrm{T}=25.0{ }^{\circ} \mathrm{C}$.
a) $\left[\mathrm{HClO}_{4}\right]=1.0 \underline{\mathrm{M}}$
b) $\left[\mathrm{HClO}_{4}\right]=0.1 \underline{\mathrm{M}}$

Figure 2. Hypothetical structure of tetradentate complexes of $\mathrm{NpO}_{2}{ }^{+}$with Chlorophosphonazo III.
a) bidentate species
b) tetradentate species

Figure 3. First order rate constants for $\mathrm{NpO}_{2}{ }^{+}+\mathrm{CLIII}$ at $4.0 \times 10^{-5} \underline{\mathrm{M}} \mathrm{CLII}, 0.1 \underline{\mathrm{M}}$ $\mathrm{HClO}_{4}, \mathrm{~T}=25.0^{\circ} \mathrm{C}, \mathrm{I}=1.0 \underline{\mathrm{M}}$ as a function of $\left[\mathrm{NpO}_{2}{ }^{+}\right]$.

Figure 4. Isokinetic plot for the reactions of $\mathrm{NpO}_{2}^{+}, \mathrm{UO}_{2}{ }^{2+}, \mathrm{Th}^{4+}$, and $\mathrm{Zr}^{4+}$ with CLIII.

Figure 5. Correlation of second order complex formation rates of $\mathrm{Fe}^{3+}, \mathrm{Zr}^{4+}, \mathrm{La}^{3+}$, $\mathrm{Eu}^{3+}, \mathrm{Dy}^{3+}, \mathrm{Th}^{4+}, \mathrm{UO}_{2}{ }^{2+}, \mathrm{NpO}_{2}{ }^{+}$with $\mathrm{CLIII}$ as a function of cation radius. 
Table 1. Resolved rate constants $\left(\mathrm{k}_{\mathrm{sl}}, \mathrm{k}_{\mathrm{int}}\right)$ for the reaction of $\mathrm{NpO}_{2}{ }^{+}+\mathrm{CLIII}$ as a function of temperature and $\left[\mathrm{H}^{+}\right]$at $\mathrm{I}=1.0 \mathrm{M},[\mathrm{CLIII}]=4.0 \times 10^{-5} \underline{\mathrm{M}},\left[\mathrm{NpO}_{2}+\right]$ from $1 \times 10^{-5}$ to $1 \times 10^{-4} \underline{\mathrm{M}}$.

\begin{tabular}{cccc}
\hline$\left[\mathrm{HClO}_{4}\right](\mathrm{M})$ & $\mathrm{k}_{\text {slope }}\left(/ 10^{4}\right)\left(\mathrm{M}^{-1} \mathrm{sec}^{-1}\right)$ & $\mathrm{k}_{\text {int }}\left(\mathrm{sec}^{-1}\right)$ & $\mathrm{T}( \pm 0.1)(\mathrm{C})$ \\
\hline 0.1 & $2.22( \pm 0.14)$ & $3.101( \pm 0.078)$ & 5.1 \\
0.3 & $1.99( \pm 0.08)$ & $4.344( \pm 0.045)$ & 5.1 \\
0.5 & $2.88( \pm 0.13)$ & $5.133( \pm 0.072)$ & 5.1 \\
0.7 & $2.41( \pm 0.12)$ & $5.846( \pm 0.064)$ & 5.0 \\
1.0 & $3.21( \pm 0.11)$ & $6.443( \pm 0.062)$ & 5.0 \\
0.1 & $3.86( \pm 0.36)$ & $4.606( \pm 0.209)$ & 9.9 \\
0.3 & $4.87( \pm 0.08)$ & $5.014( \pm 0.042)$ & 9.9 \\
0.5 & $4.85( \pm 0.06)$ & $6.360( \pm 0.033)$ & 9.9 \\
0.7 & $4.98( \pm 0.14)$ & $7.573( \pm 0.079)$ & 9.9 \\
1.0 & $5.92( \pm 0.81)$ & $8.298( \pm 0.421)$ & 9.9 \\
0.1 & $6.24( \pm 0.12)$ & $5.467( \pm 0.044)$ & 14.9 \\
0.3 & $6.80( \pm 0.14)$ & $7.979( \pm 0.051)$ & 14.9 \\
0.5 & $7.14( \pm 0.21)$ & $9.985( \pm 0.078)$ & 14.9 \\
0.7 & $7.07( \pm 0.32)$ & $11.91( \pm 0.02)$ & 14.9 \\
1.0 & $7.57( \pm 0.19)$ & $13.59( \pm 0.07)$ & 14.9 \\
0.1 & $8.14( \pm 0.43)$ & $8.610( \pm 0.162)$ & 20.0 \\
0.3 & $5.82( \pm 0.14)$ & $12.92( \pm 0.05)$ & 20.0 \\
0.5 & $7.95( \pm 0.26)$ & $15.83( \pm 0.10)$ & 20.0 \\
0.1 & $11.56( \pm 1.13)$ & $12.43( \pm 0.95)$ & 25.0 \\
0.3 & $11.35( \pm 0.63)$ & $17.31( \pm 0.52)$ & 25.0 \\
0.5 & $14.03( \pm 1.53)$ & $24.53( \pm 0.75)$ & 25.0 \\
0.7 & $14.12( \pm 0.24)$ & $27.38( \pm 0.24)$ & 25.0 \\
1.0 & $12.91( \pm 3.89)$ & $28.80( \pm 2.49)$ & 25.0 \\
\hline
\end{tabular}

${ }^{\mathrm{a}} 1 \times 10^{-5} \leq[\mathrm{Np}(\mathrm{V})] \leq 8 \times 10^{-5} \underline{\mathrm{M}}, \mathrm{CLIII}=4 \times 10^{-5} \underline{\mathrm{M}}, \mathrm{I}=1.0 \underline{\mathrm{M}}$ maintained with $\mathrm{NaClO}_{4}$. 
Table 2. Derived rate constants for complex formation $\left(k_{1}\right)$ and dissociation $\left(k_{2}\right.$-acid independent, $\mathrm{k}_{3}$-acid dependent) for $\mathrm{NpO}_{2}{ }^{+}+\mathrm{CLIII}$ at $1.0 \underline{\mathrm{M}}$ ionic strength. ${ }^{\mathrm{a}}$

\begin{tabular}{cccc}
\hline $\mathrm{k}_{1}\left(\underline{\mathrm{M}}^{-1} \mathrm{sec}^{-1}\right)\left(\mathrm{x} 10^{4}\right)$ & $\left.\mathrm{k}_{2} \mathrm{sec}^{-1}\right)$ & $\mathrm{k}_{3}\left(\underline{\mathrm{M}}^{-1} \mathrm{sec}^{-1}\right)$ & $\mathrm{T}( \pm 0.1)(\mathrm{C})$ \\
\hline $2.541( \pm 0.117)$ & $3.56( \pm 0.09)$ & $3.14(0.49)$ & 5.1 \\
$4.894( \pm 0.288)$ & $5.30( \pm 0.14)$ & $3.64(0.59)$ & 9.9 \\
$6.966( \pm 0.192)$ & $9.14( \pm 0.16)$ & $4.94(0.79)$ & 14.9 \\
$7.306( \pm 0.276)$ & $17.59( \pm 0.38)$ & $7.34(0.79)$ & 20.0 \\
$12.79( \pm 1.48)$ & $22.53( \pm 2.67)$ & $11.22(4.56)$ & 25.0 \\
\hline
\end{tabular}

$\mathrm{ak}_{\mathrm{obs}}=\mathrm{k}_{1}[\mathrm{~Np}(\mathrm{~V})]+\mathrm{k}_{2}+\mathrm{k}_{3}\left[\mathrm{H}^{+}\right]$ 
Table 3. Activation parameters for the complex formation and dissociation reactions of $\mathrm{Np}(\mathrm{V})$ - CLIII.

\begin{tabular}{cccc}
\hline Rate Parameter & $1(\underline{\underline{M}})$ & $\Delta \mathrm{H}^{*}(\mathrm{~kJ} /$ mole $)$ & $\Delta \mathrm{S}^{*}(\mathrm{~J} /$ mole K$)$ \\
\hline $\mathrm{k}_{\mathrm{f}}$ & 1.0 & $46.2(0.3)$ & $7( \pm 1)$ \\
$\mathrm{k}_{\mathrm{rd}}$ & 1.0 & $38.8(0.6)$ & $-96( \pm 18)$ \\
$\mathrm{k}_{\mathrm{ri}}$ & 1.0 & $70.0(0.1)$ & $17(1)$ \\
$\mathrm{k}_{\mathrm{f}}$ & 0.1 & $60.5(3.4)$ & $62(1)$ \\
\hline
\end{tabular}



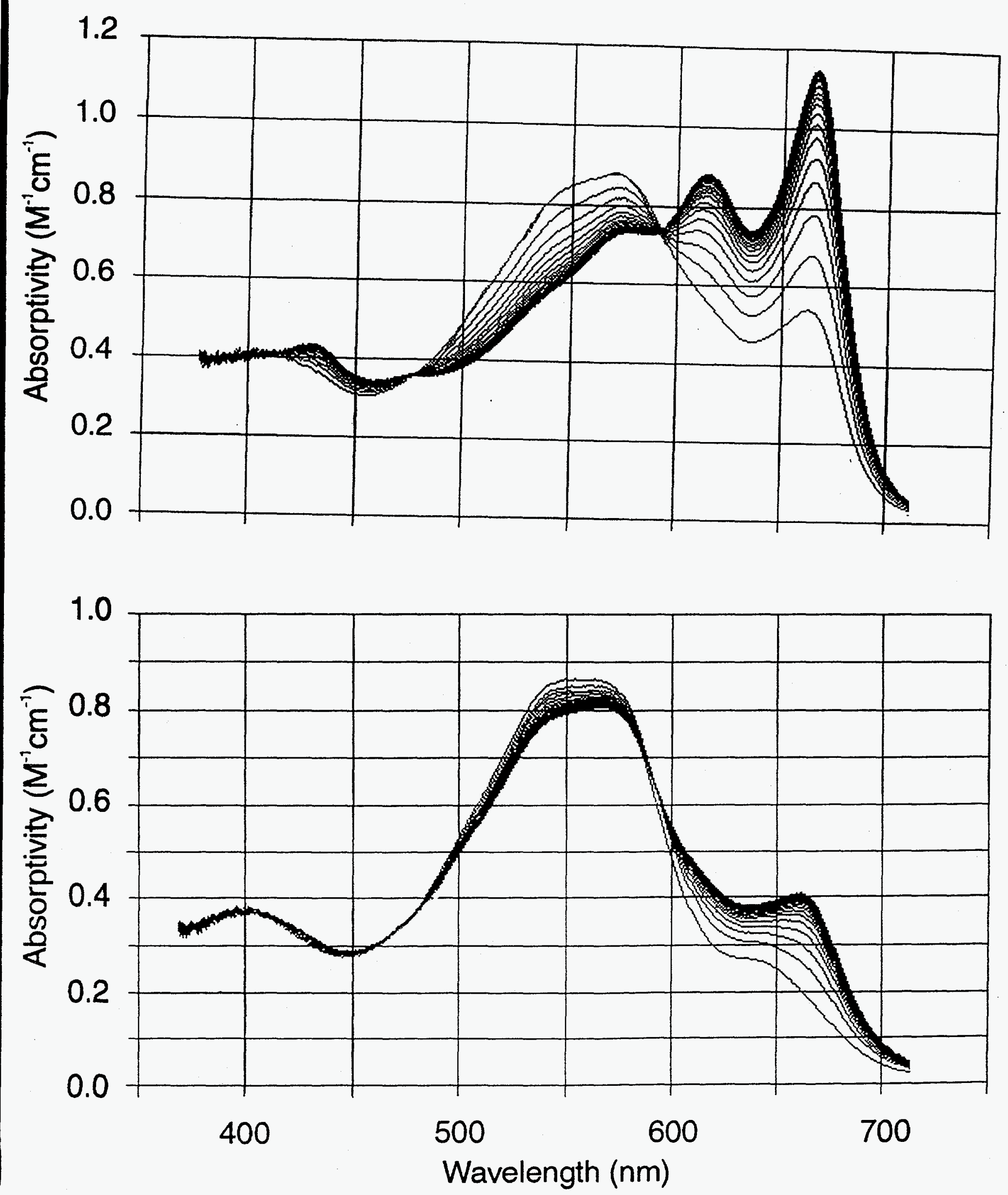


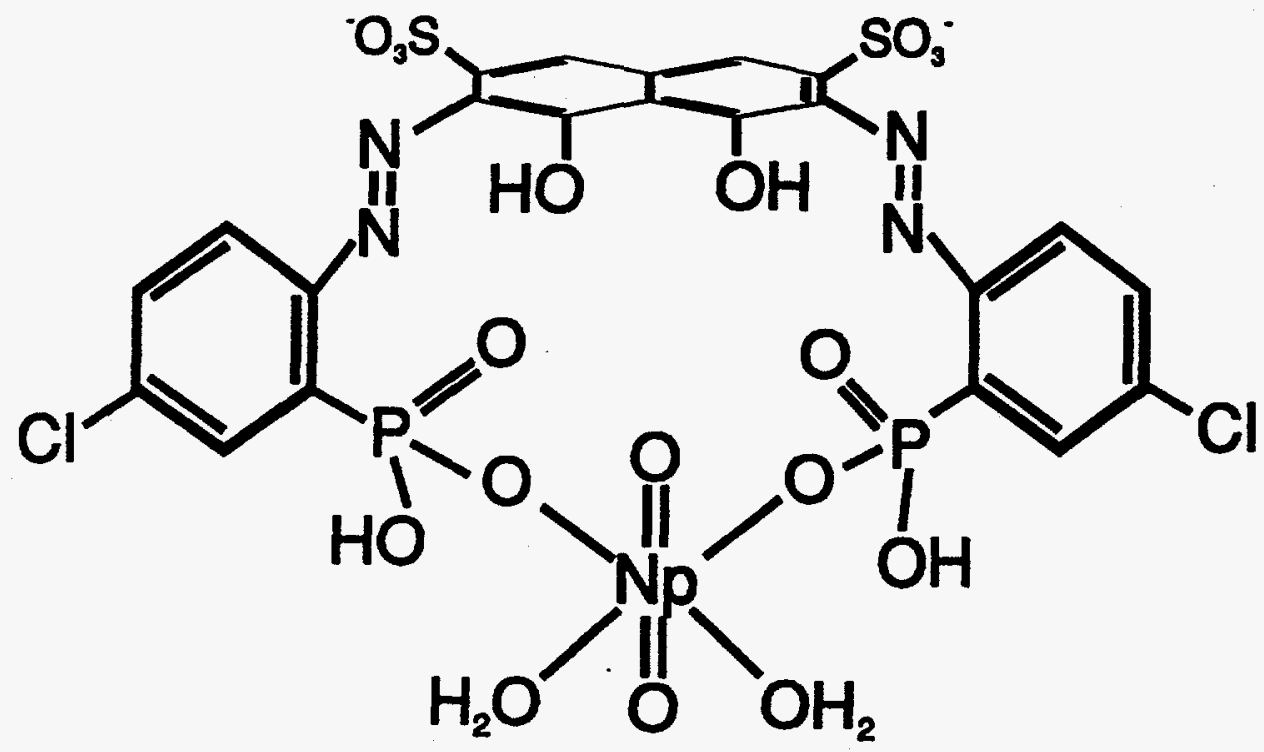

a

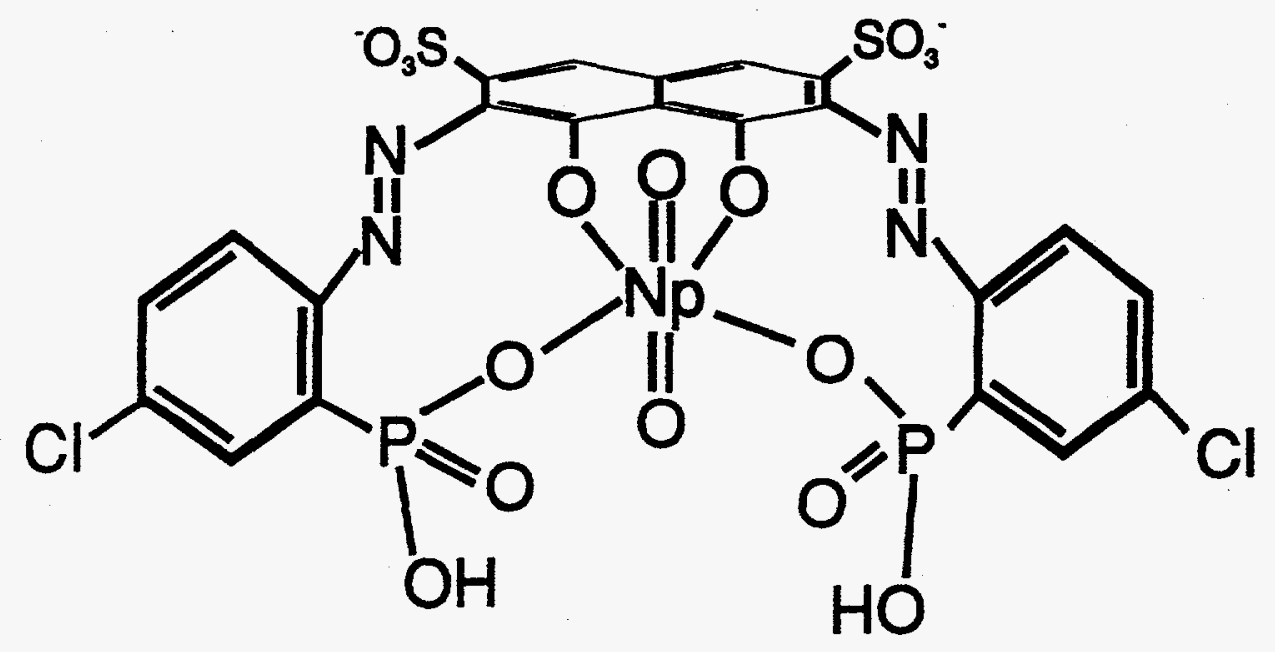

b 


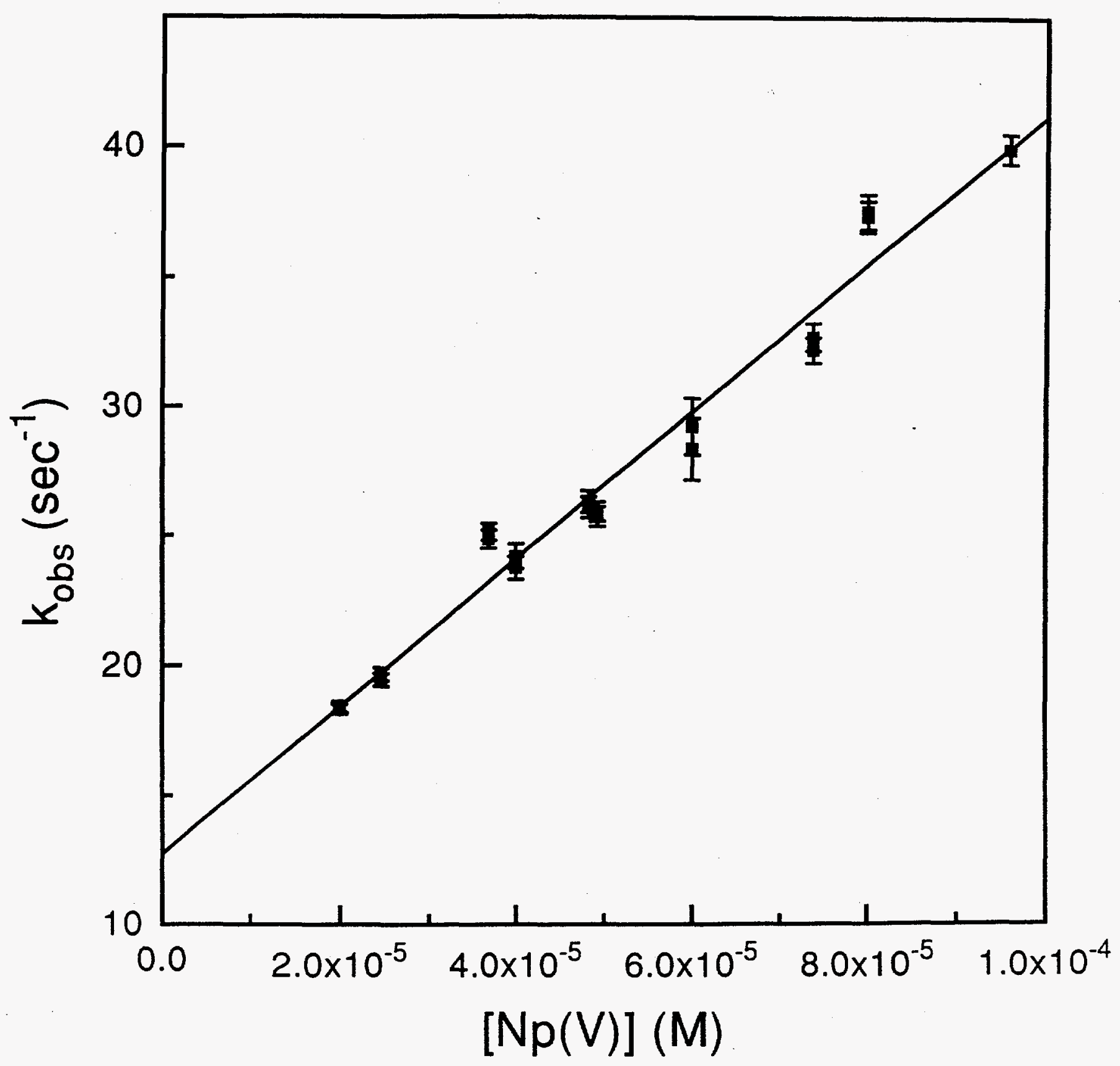




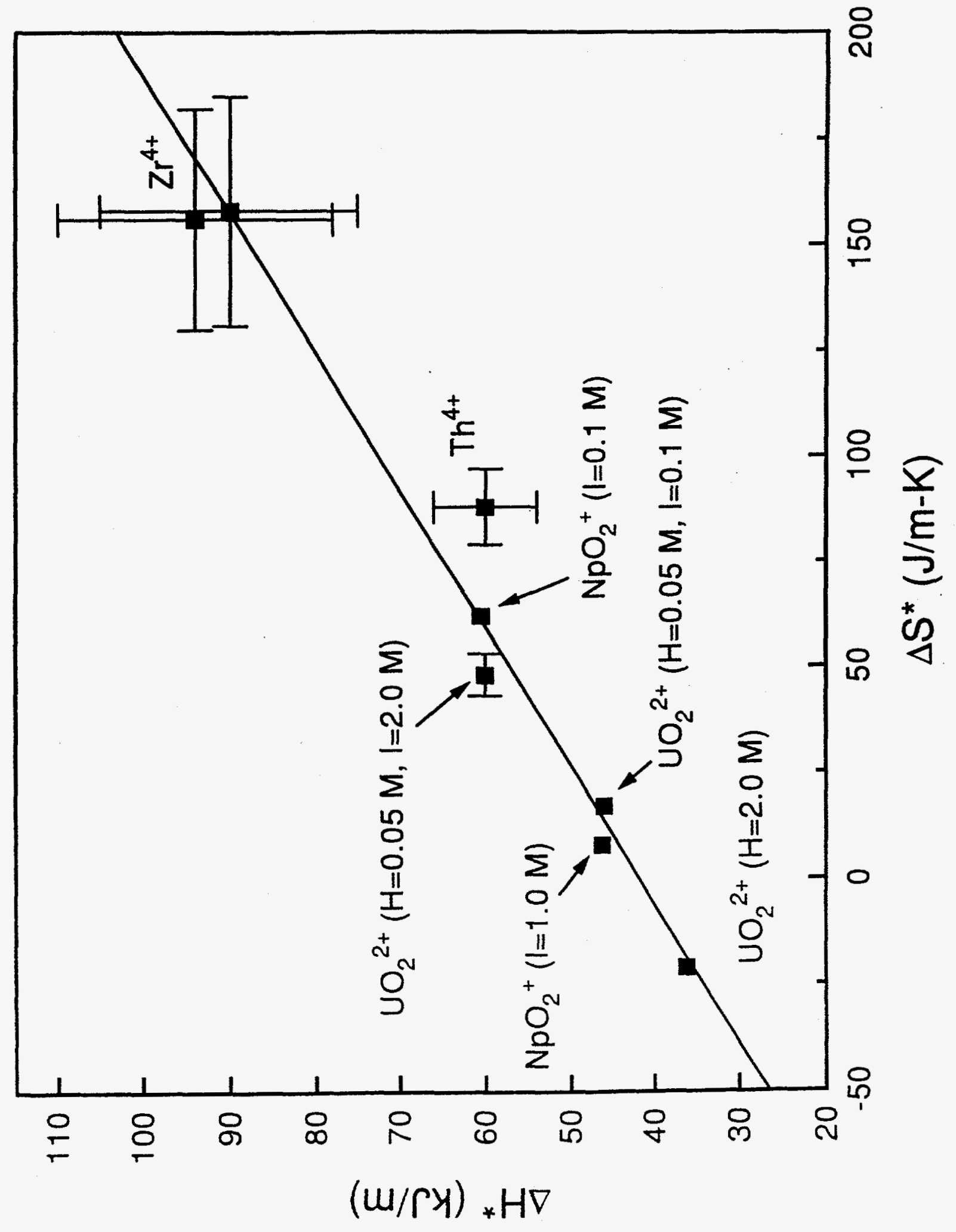




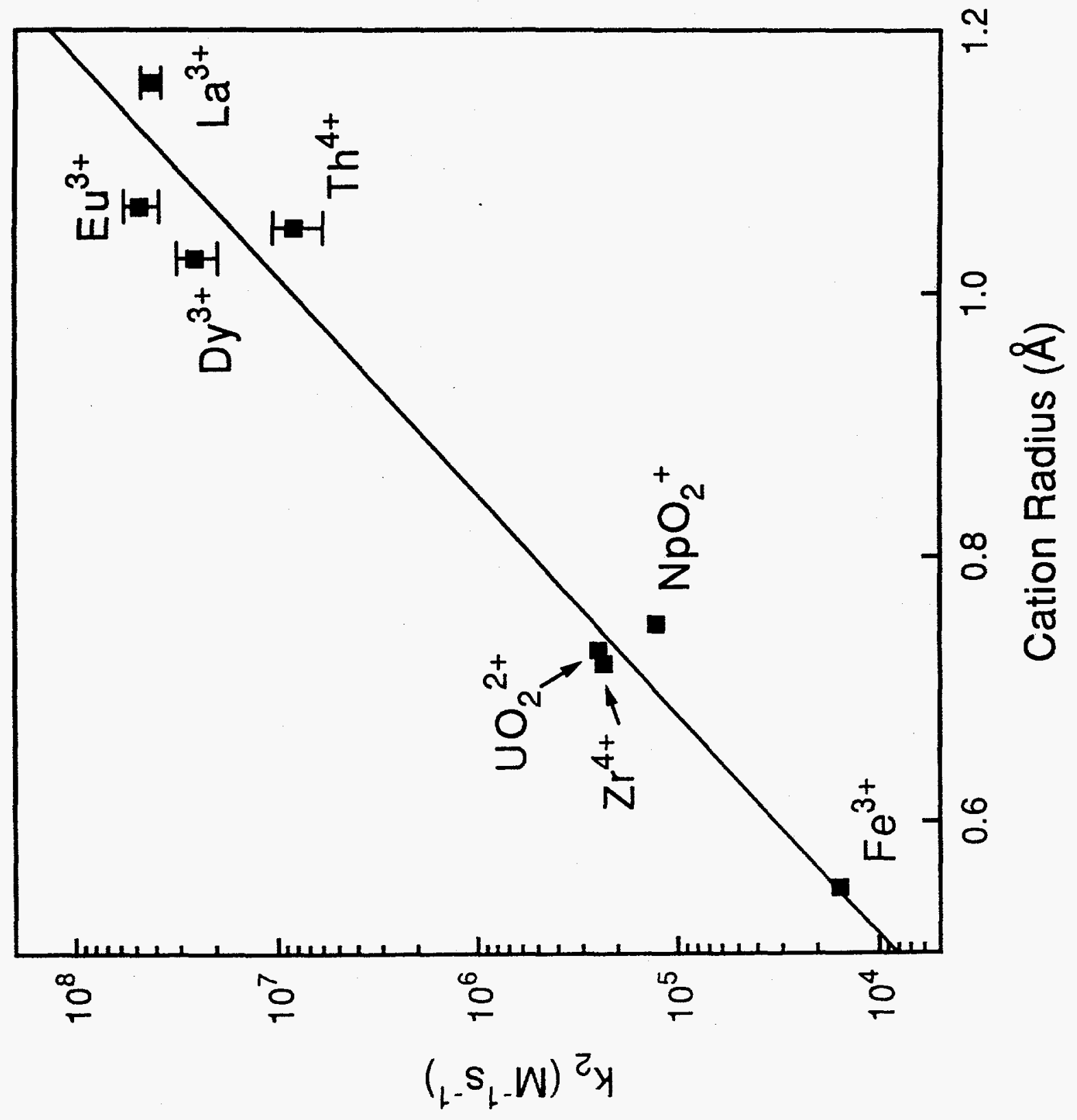

